\title{
SETTING PEOPLE UP FOR SUCCESS: HOW THE PORTMAN RITZ- CARLTON HOTEL GETS THE BEST FROM ITS PEOPLE
}

\section{ARTHUR YEUNG}

In China, where many multinational companies face a constant shortage of talent and high employee turnover, the Portman Ritz-Carlton Hotel has been able to attract, develop, and retain high-quality talent to deliver excellent customer service and ensure profitable growth. Under the leadership of Mark DeCocinis since 1998, the Portman Ritz-Carlton has not only been named as the "Best Employer in Asia" by Hewitt Associates three consecutive times, but has also rated the highest in employee satisfaction among all of the Ritz-Carlton's 59 hotels worldwide for five consecutive years. How can DeCocinis and his leadership team achieve such remarkable results? In his interview with Arthur Yeung, Mark DeCocinis, general manager of the Portman Ritz-Carlton and regional vice president, Asia-Pacific, of the Ritz-Carlton Hotel Company, shares his philosophy and practices on talent management in China and elsewhere. (c) 2006 Wiley Periodicals, Inc.

rior to 1998, the Portman Hotel in Shanghai was a five-star property much like any other in the city. Employee and guest satisfaction ranged between 70 and 80 percent, and finances were unspectacular. But after Mark DeCocinis and Ritz-Carlton took over management of the hotel in early 1998, employee satisfaction soared, guests were much happier, and finances improved. In just a few years, General Manager DeCocinis and Ritz-Carlton lifted the hotel to a level all its own, using a proven business approach and sound human resource management practices. In recent years, the Portman Ritz-Carlton has won award after award in recognition of its successful formula. For three consecutive years, it was named "Best Employer in Asia" by Hewitt Associates and "Overall Best Business Hotel in Asia" by Bloomberg TV. For the fifth time, it has been selected the "Best Business Hotel in China" by Business Asia magazine. For five consecutive years, its annual employee satisfaction rate has been the highest among all of the Ritz-Carlton's 59 hotels worldwide, reaching

Correspondence to: Arthur Yeung, Philips Chair Professor of Human Resource Management, China Europe International Business School, 699 Hongfeng Road, Shanghai 201206 PRC. E-mail: ayeung@ceibs.edu 
98 percent last year. And while the staff turnover rate for Asia's hotel industry is 29 percent, the rate at the Portman Ritz-Carlton is a modest 15 to 16 percent.

In China, where many multinational companies face a constant shortage of talent and high employee turnover, how does the Portman Ritz-Carlton cope with these challenges to ensure sustainable growth? While other multinational companies may find local service attitudes and skills deficient, how is the Portman Ritz-Carlton able to ensure the high quality of guest relations consistent with the hotel chain's properties elsewhere? What have DeCocinis and his leadership team done to transform an ordinary hotel into one of the Best Employers in Asia and achieve the highest rate of employee satisfaction among all Ritz-Carlton hotels worldwide?

In the following interview, Mark DeCocinis, general manager of the Portman RitzCarlton and regional vice president, Asia-Pacific, of the Ritz-Carlton Hotel Company, shares his successful formula with Arthur
Yeung, Philips Chair Professor of Human Resource Management at the China Europe International Business School.

Arthur Yeung: The Portman Ritz-Carlton has been consistently elected the Best Employer in Asia. What's your secret to success in people management?

Mark DeCocinis: The secret is consistency in execution. Our priority is taking care of our people. We're in the service business, and service comes only from people. It's about keeping our promise to our employees and making that an everyday priority. Our promise is to take care of them, trust them, develop them, and provide a happy place for them to work. The key is everyday execution.

AY: How do you know your employees are being taken care of every day?

MD: We look at each other, and we smile at each other. You can feel that people are engaged. In a survey just completed, we scored 98 percent in overall employee satis-

\section{S I D E B A R Mark DeCocinis and Portman Ritz-Carlton}

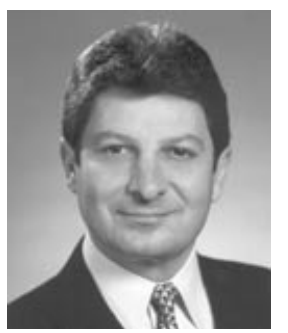

A native of Salerno, Italy, Mark DeCocinis was brought up in the United States. He brings more than 20 years of hotel experience to his position. He was formerly general manager of the Ritz-Carlton Aspen, following posts as hotel manager and general manager of the Ritz-Carlton San Francisco. He has held food and beverage director positions at Ritz-Carlton hotels and resorts in Amelia Island, Naples (Florida), and Boston, Massachusetts. During his 16 years with the company, Mark DeCocinis has been a member of the Ritz-Carlton hotels and resorts pre-opening teams in Asia and the United States.

The 578-room Portman Ritz-Carlton Shanghai is a landmark located in a retail, dining, and entertainment complex on the famous Nanjing Road. Under his leadership, DeCocinis has led the Portman Ritz-Carlton to win multiple outstanding awards. In recognition of his contributions to Shanghai's economic and social development, DeCocinis was made a permanent resident of China this year and honored with the Gold Quality Award by the Shanghai Municipal Government. He also received the Friendship Award from the People's Republic of China in 2004, Shanghai's prestigious Magnolia Gold Award in 2003, and the Magnolia Silver Award in July 2001.

The Ritz-Carlton Hotel Company, LLC, of Chevy Chase, Maryland, currently operates 59 hotels in the Americas, Europe, Asia, the Middle East, and Africa. Over 20 projects are under development around the globe, with hotel openings planned for Grand Cayman, Moscow, and Beijing (2) over the next year. The Ritz-Carlton Guangzhou will open in 2007, while the Ritz-Carlton Shenzhen opening is scheduled for 2008. The Ritz-Carlton is the only service company to have twice earned the prestigious Malcolm Baldrige National Quality Award, which recognizes outstanding customer service. 
faction. For the last five years, we've had the highest satisfaction rate of all the Ritz-Carlton properties worldwide in an annual survey.

Of course we have employee issues, but we work together to solve them. We communicate what actions can and are being taken. Most things that cause satisfaction are small and can be corrected every day; for example, does my uniform fit well and is it clean, is the food for employees good, or is the work environment clean and is it representative of the public areas? In our hotel, where we work and where we rest have the same standard as the public areas. That's what "ladies and gentlemen serving ladies and gentlemen" means to me.

These are little things. For the bigger things, we also communicate so employees understand and we work together to solve them. If it's a money issue, we work it out. If it's a construction or purchasing issue, we talk about it.

Employee satisfaction involves trust, communication, involvement, and engagement. There's also another word we often use: empowerment. We allow them to do what is necessary to take care of customers. We select the best people, we train them, give them the environment to do the job, and allow them freedom to do the job. Everyone feels very good about having that ownership and that purpose.

AY: The idea is to set up people for success so they have pride in their jobs. But in China, where employees have relatively poor service attitudes and skills, what management practices do you put in place to help them succeed?

MD: The key starts with selecting the right people. Our selection focuses on talent and personal values because these are things that can't be taught. Our culture is special, and we can't expect to bring someone into this culture if they don't have the same values and purpose.

We focus on a person's theme. What do they enjoy? What's their purpose in life? What motivates them? We look for people who genuinely enjoy contact with people and helping others. It's not about being introverted or extroverted; it's about caring for and respecting others. You can work at the front desk or behind the scenes, but you must enjoy contact with others, whether they are guests or other employees.

AY: What's the hiring process to ensure you've selected the right candidate?

MD: Candidates apply for a position and are interviewed by Human Resources. If they pass this interview, they interview with the manager to learn more about their skills, then have a final interview with the division head and general manager. So it's really a group decision.

The general manager is involved in the interview process of all employees, to show the importance of that individual to the company. In $99 \%$ of the cases, I usually agree with the selection decision.

AY: In most companies, the general manager is not involved in the selection of frontline employees. What do you ask durOur culture is special, and we can't expect to bring someone into this culture if they don't

have the same values and purpose. ing these interviews?

MD: I usually ask them about themselves and try to make a connection. But the important question is: why do you want to join? Whatever they say, the most important notion needs to be "I enjoy working with people," not just using the phrase "I like people." Do they have a genuine connection with people? And are they fulfilled in making people happy?

I really want to find out what motivates them. If the person smiles naturally, that's very important to us, because this is something you can't force. And if you're happy on the inside, you're happy on the outside. That makes others feel good.

AY: Do you find it difficult to find good people in China? Many executives here complain about the talent shortage they face. Does the Ritz-Carlton experience a similar challenge? 
MD: It certainly is a challenge in China. I believe part of it is due to the growth and prosperity of China. We have some positions that are more difficult to fill than others, but I would say they are very rare. Overall, we don't have an issue finding talent. We have a talent bank and have people waiting for positions. We have trainees from universities who work as interns for several months. We also have employees recommend others when we do have openings. So, we're not having difficulty filling positions.

We're very fortunate that our turnover is low. This is partly because we look at it as a long-term relationship and we try to select candidates who also seek a long-term relationship. When someone is applying for a cook's position, I will ask him if he would like to be an executive chef someday. You can see from his expression he is thinking, "I can't believe it. I've not even been selected as a cook and I'm being asked if I want to be an executive chef!" If you put that idea in their mind in the beginning, it shows them there is a future for them and that you also see that future.

AY: How many people are promoted from within? What's the average tenure of employees here?

MD: Many senior positions are filled from within the hotel or within the com- pany, approximately 70 to 80 percent of the leadership positions. We took over management of the hotel in January 1998. Over 60 percent of the employees have a tenure of more than five years, and over 30 percent have a tenure of eight years or more.

AY: Besides the selection process, what else does the Ritz-Carlton do to motivate its employees to provide excellent service?

MD: We spend two days of orientation with new employees before they come into contact with any guest. They must understand our culture and philosophy. The general manager, the executive team or guidance team, and HR are all involved. Each of them explains our Credo (we are here to take care of our guests); our Employee Promise (we are here to take care of you); our 20 Basics; and our Motto (we are ladies and gentlemen taking care of ladies and gentlemen) [see Figures 1 and 2].

Then they receive 30 days of training with a certified trainer from the department. Following that, we have reinforcement training on the 21st day and we get feedback on how we can improve our training program for future retraining and recertification. Then, throughout the year we provide a minimum of 130 hours of training for every employee, including specific training for

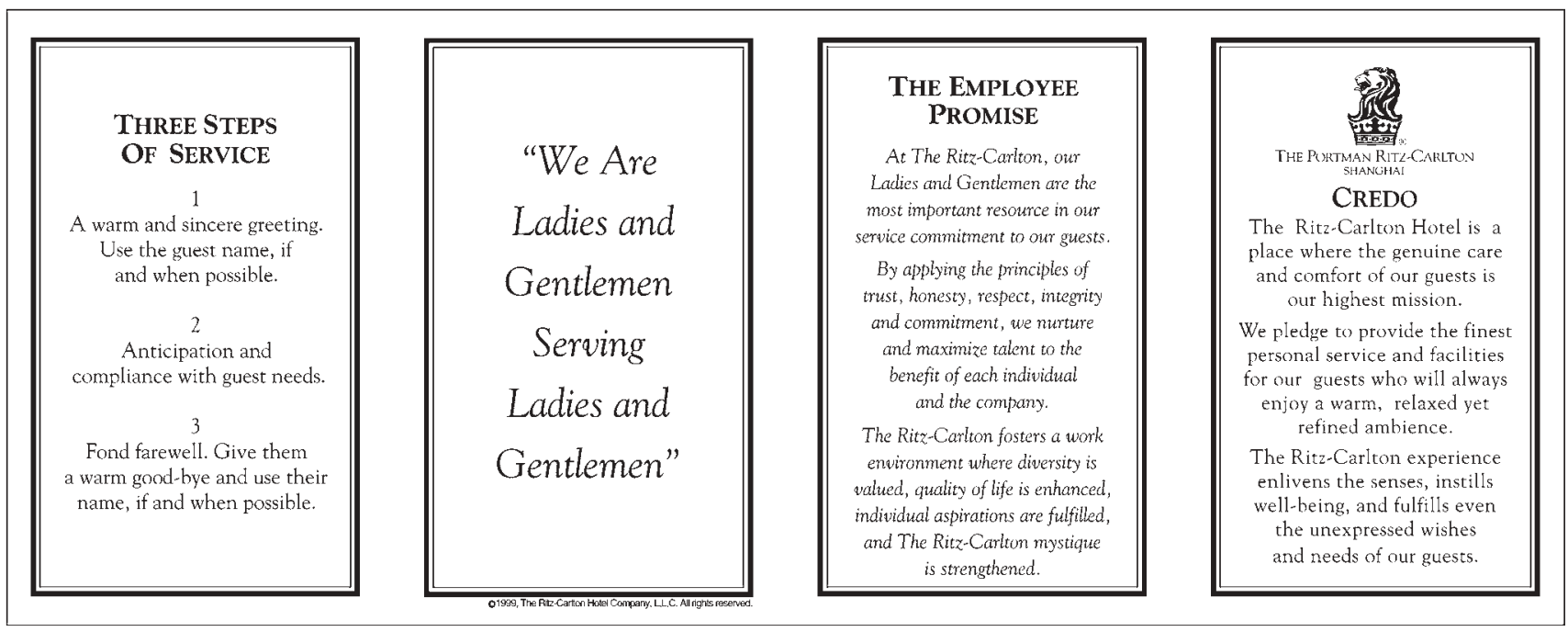

FIGURE 1. Ritz-Carlton: Motto, Employee Promise, and Credo 


\begin{tabular}{|c|c|c|c|c|}
\hline $\begin{array}{l}\text { THE RITZ-CARLTON }{ }^{\text {(i) }} \text { BASICS } \\
\text { The Credo is the principle belief of our } \\
\text { Company. It must be known, owned } \\
\text { and energized by all. } \\
\text { Our Motto is: "We Ate Ladies and } \\
\text { Gentlemen Serving Ladies and } \\
\text { Gentlemen". As service professionals, } \\
\text { we treat our guests and each other with } \\
\text { respect and dignity. } \\
\text { The Three Steps of Service are the } \\
\text { foundation of Ritz-Carlton hospitality. } \\
\text { These steps must be used in every } \\
\text { interaction to cnsure satisfaction, } \\
\text { retention and loyalty. } \\
\text { The Employee Promise is the basis for } \\
\text { our Ritz-Carlton work environment. It } \\
\text { will be honored by all employees. } \\
\text { All employees will successfully com- } \\
\text { plete annual Training Certification for } \\
\text { their position. } \\
\text { Company objectives are communicat- } \\
\text { ed to all employees. It is everyone's } \\
\text { responsibility to support them. }\end{array}$ & $\begin{array}{l}\text { 7. To creare pride and joy in the work- } \\
\text { place, all employees have the right to } \\
\text { be involved in the planning of the } \\
\text { work that affects them. } \\
\text { 8. Each employee will continutously iden- } \\
\text { tify defects (M.R. B.I.V.) throughout } \\
\text { the Hotel. } \\
\text { 9. It is the responsibility of each employ- } \\
\text { ee to create a work environment of } \\
\text { teamwork and lateral service so that } \\
\text { the needs of our guests and each other } \\
\text { are met. } \\
\text { 10. Each employee is empowered. For } \\
\text { example, when a guest has a problem } \\
\text { or necds something special you } \\
\text { should break away from your regular } \\
\text { duties, address and resolve the issue. } \\
\text { 11. Uncompromising levels of cleanli- } \\
\text { ness are the responsibility of every } \\
\text { employee. } \\
\text { 12. To provide the finest personal service } \\
\text { for our guests, each employee is } \\
\text { tesponsible for identifying and record- } \\
\text { ing individual guest preferences. }\end{array}$ & 13. & $\begin{array}{l}\text { Never lose a guest. Instant guest } \\
\text { pacification is the responsibility of } \\
\text { each employee. Whoever receives a } \\
\text { complaint will own it, resolve it to } \\
\text { the guest's satisfaction and record it. } \\
\text { "Smile - We are on stage." Always } \\
\text { maintain positive eye contact. Use } \\
\text { the proper vocabulary with our } \\
\text { guests and each other. (Use words } \\
\text { like- "Good Morning," "Certainly," } \\
\text { "['ll be happy to" and "My pleasure".) } \\
\text { Be an ambassador of your Hotel in } \\
\text { and outside of the workplace. } \\
\text { Always speak positively. Communi- } \\
\text { catc any conccrns to the appropriate } \\
\text { person. } \\
\text { Escort guests rather than pointing } \\
\text { out directions to another area of the } \\
\text { Hotel. } \\
\text { Use Ritz-Carlton telephone eti- } \\
\text { quette. Answer within three rings } \\
\text { and with a "smile". Use the guest's } \\
\text { name when possible. When neces- } \\
\text { sary, ask the caller "May I place you }\end{array}$ & $\begin{array}{l}\text { on hold?" Do not screen calls. } \\
\text { Eliminate call transfers whenever } \\
\text { possible. Adhere to voice mail stan- } \\
\text { dards. } \\
\text { 18. Take pride in and care of your per- } \\
\text { sonal appearance. Everyone is } \\
\text { responsible to convey a professional } \\
\text { image by adhering to Ritz-Carlton } \\
\text { clothing and gronming standards. } \\
\text { 19. Think safety first. Each employee is } \\
\text { responsible for creating a safe, secure } \\
\text { and accident free environment for } \\
\text { all guests and each other. Be aware of } \\
\text { all fire and safety emergency proce- } \\
\text { dures and report any security risks } \\
\text { immediately. } \\
\text { 20. Protecting the assets of a Ritz- } \\
\text { Carlton hotel is the responsibility of } \\
\text { every employee. Conserve energy, } \\
\text { properly maintain our hotels and } \\
\text { protect the environment. }\end{array}$ \\
\hline
\end{tabular}

FIGURE 2. The 20 Ritz-Carlton Basics

their department and training on culture, language, and computer skills.

At the start of every shift, we also have a daily line-up or briefing for every department that lasts 15 to 20 minutes. Different departments may conduct briefings differently, but one thing that's consistent is the message. We talk about one of the 20 Basics every day, and it's the same Basic that's discussed in the line-ups in Ritz-Carlton hotels throughout the world. For example, Basic 11 is "Cleanliness is important to everyone." We all discuss the same Basic with different examples. The Basics remind us of our first day at the company and they are reinforced every day. That's the answer to your first question, how do you maintain consistency?

Communication is important. Having interaction with the manager every day and speaking freely about what we enjoy and how we can improve is important. The general manager has a breakfast meeting with 10 to 15 employees from different departments once a month. We all speak openly and it's an informal gathering. The purpose is to understand what they're working on and what can be improved, and it's usually very positive. I always learn something from these meetings.

Employees also document mistakes in their department. It's very important that when someone makes a mistake that they identify the mistake so they can take action to resolve it; otherwise, the same mistakes may reoccur. So you also recognize people for taking ownership of a problem and being part of the solution.

From the employees' point of view, there's a lot of interaction with the general manager beginning with the interview. The general manager's interest in you establishes what is expected of you as you step into your work area. And with the monthly breakfasts and lunches held every month, you feel more relaxed because you already have a relationship with the general manager and you're just continuing it. There's no fear of reprimand if you say something's not working well. We don't identify a person and say you've done something wrong. We look at it in a positive way.

\section{AY: This clearly requires a lot of effort and energy to apply such employee-centric management practices. This is manage- able for the Portman Ritz-Carlton with 750 people, but what about operations with 5,000 or 10,000 people?}

MD: If you have a 5,000-person operation, you have to come up with a system to take care of 5,000 people. We don't change our values, philosophy, and culture because 
we want to grow and expand. Can the general manager be involved in the interview process if you have 5,000 staff? You have to come up with a process and system that expresses that same feeling.

When I joined the hotel, we had just opened the eighth hotel in the United States. We were going to open 18 additional hotels, and everyone speculated that the company's personalized service was going to suffer because we were going to lose our values and service. That never happened. Now, the RitzCarlton has almost 30,000 employees worldwide.

AY: You start with a philosophy that employee satisfaction leads to guest satisfaction, which in It's our priority every turn leads to good financial results. How do you know such a relationship really exists?

MD: I'll give this hotel as an

walk, starting with

me and the people

around me.
AY: If the Ritz-Carlton worldwide adopts the same culture and philosophy, what makes the Portman Ritz-Carlton the best?

MD: It's our priority every day to make sure we're walking the walk, starting with me and the people around me. The general manager and the executive team are setting an example. People believe what they see, not what is said. I can say "I care about you," but when I look you in the eye and say it, you know I mean it. I listen and take action on what you say and recognize you. Recognition is a very simple thing; it should be personal and individual. If you get to know people as individuals and recognize them the same way as guests, that means more than anything else.

AY: You mentioned the importance of role modeling, starting from the top. Looking back at the last seven or eight years, are there any major incidents that really sent a powerful message to employees that you really care?

MD: During the 2003 SARS crisis, business started to deteriorate. By April, our occupancy rate, which should have been at 85 percent, dropped to 35 percent. We told our employees that neither we nor they were the cause. These factors were out of our control. Their first thoughts were "What's going to happen to me? I have a family to take care of." The first step was for me and the executive team to take a 30 percent pay cut, and we asked everyone to work five days a week.

Then it got worse. In May, the occupancy rate was 17 to 18 percent. We reduced the workweek to four days, and people were asked to take their outstanding paid leave days. And then, when these reserves were getting used up, that's when everyone really pulled together. Employees who were single gave their shifts to colleagues who had families to support.

We also renewed contracts without a second thought. Some employees were worried that their contracts would not be renewed given the low occupancy rates, but we told them if their performance and behavior were good, of course we would keep them on. Our employee satisfaction rate that year was 99.9 
percent. We used to have a high level of trust with employees, but it got even better. This was one of those negative things that turned out to be extremely positive.

AY: When you took over the Portman in late 1997, the number of employees was higher. Can you talk about the transition period?

MD: I arrived three months prior to the January 1, 1998, handover of management. The hotel didn't stop operating; it just changed its name. We had 1,060 employees then, and we wanted to keep everyone. We told them that we're a good company and we take care of people. We would work with them and train them, but we expected them to perform. We were there to take care of each other and our guests; we were not there for individual benefit. But there were a number of employees who were there for their own benefit. They were in business for themselves.

AY: Some of the early employees were there for personal gain. Do you mean integrity problems?

MD: Of course. We didn't select them. Even though people liked what we represented, they didn't have the same intensity, energy, or purpose. We had to find out by working together. We gave everybody the opportunity, but there are people who don't fit the Ritz-Carlton culture. We had a high turnover the first two years, 20 to 25 percent. Some left and others we let go. We didn't let go of anyone in the first six months because we needed to observe them.

When we took over, there were a lot of people standing around complaining, "The work is hard; we need more people." But in fact, there was a lot of waste in the system. To make things more efficient, we combined jobs, cross-trained, and offered better pay.

Employee satisfaction was 71 percent in 1998, and at the end of the first year it was 72 percent. Guest satisfaction was 80 percent. Then we had a complete renovation of the hotel. The first two years was about learning and understanding and about moving forward. By the end of 1999, I realized that we had gone through the most difficult period. Then things started to turn around.

We noticed that on the employee surveys, about 40 percent were in the middle; they didn't agree or disagree. So we told them, "Look, we're doing our best. We're communicating with you. If we're doing a good job, tell us. If we're not doing a good job, tell us. It doesn't help us if you stay in the middle." They were afraid to tell us we were doing a good job, thinking we might relax, but we didn't. That was the breakthrough, and that's when trust was built.

We have 780 employees now. Employees who can do multiple tasks are recognized and rewarded. Through training, you have consistency in the leadership, which improves efficiency. And we pay them well. If you expect your people to be the best, you must pay at the top of the market.

AY: Based on your extensive management experience in many countries, how does talent management in China compare with Ritz-Carlton elsewhere?

People have pride and want to express themselves and they want to have the freedom to do their jobs.

MD: People are the same everywhere. Everyone wants to be treated with respect as an individual. You hear this saying: In Asia, people want their boss to tell them what to do. But this isn't true here-not in Japan, not in Korea, not in Indonesia. People have pride and want to express themselves and they want to have the freedom to do their jobs. Everyone wants the support to do their jobs. That's the best benefit of Ritz-Carlton.

What's the difference between China and other countries? I've opened many hotels in Asia, but I chose to come to Shanghai because it's such an exciting city and it has such great potential. I've worked with Chinese people before and I admire them. They work very hard, are nice, and have good values. It's in line with our company. Yes, you have to be patient, you have to listen and understand, and believe in relationships. That's your foundation-build the relation- 
ship and get understanding first. And when we bring leaders from elsewhere to Shanghai, we have to pick people who can adapt to the culture here.

If you respect someone, you say nice things but also things that help them improve. If you don't care, you wouldn't say anything. Many times we have had employees who say they want to join another company for a higher salary. We will say to them, "Look, I want to make sure this is a good opportunity for you. Have we exhausted all the opportunities for you and can't provide this for you?" I will always ask, "Have you talked with your family?" Many times their family will not

I always like to want them to leave because they see they are very happy here.

focus on the

positive and look at

AY: You mentioned that people are similar whether they're people and how they can be part of something good and create something, rather than try to make myself look from Japan or Indonesia. This observation is different from other expatriates who say you need to pay attention to crosscultural differences. What are your thoughts on this?

MD: I hate making general statements about people. That's really a mistake. Everyone is different. Of course, the culture representing that country is pretty similar, but to say that Chinese people are like this and Japanese people are like that, these are stereotypes and I don't think it's fair.

But to say expatriates believe this, I have to believe you. I hear that. I always like to focus on the positive and look at people and how they can be part of something good and create something, rather than try to make myself look more important. I think being humble is the best. I've learned so much in the time I've been here and I'm still learning so much. I've received the best education of my life in these eight years. So I think those generalizations are a misconception. We're here as foreigners to share our experience and we bring something good to every country in which we work. But we also learn a great deal, and that's something that needs to be recognized.
AY: Is it fair to say that despite some national differences, Ritz-Carlton selects a certain type of person to fit your company culture and reinforces the company culture so it's consistent worldwide?

MD: Absolutely. Look at the leadership team for all these new hotels. In China, we have six other hotels and we have another 10 to 12 hotels opening in the next two to three years. The general managers will all come from within the Ritz-Carlton, because the leadership of the hotel must be someone who understands and has experienced our culture and standards. Some of the senior leadership will come from RitzCarlton and some will come from outside the company.

In China alone, we'll need 4,000 employees in the next few years, and 95 percent will come from local cities. We'll need 60 general managers and senior executives or guidance team leaders and 250 department heads. We don't have that many resources within the company. We'll take people from within the company that are being developed in other hotels in Asia and internationally. It's important to have people who have worked in China and have some language skills, so there'll be a core of people from here, Hong Kong, Singapore, and other parts of Asia. Also, there'll be people from Europe, the Middle East, or the United States.

We'll also look at people from other companies. We've had many people approach us already. I feel very good about our people. For all these new hotel openings in the next two years, I've filled over 60 percent of the senior positions. We've filled most of the jobs that are starting this year and at the beginning of 2007. We've already received many résumés from managers and employees in the cities we're opening, and we've not even started recruitment yet.

I've been going to Beijing for eight years, and people who know that we're opening in Beijing are sending me résumés and are saying that we want to join you because of your reputation as the Best Employer and because of your company culture. 
ARTHUR YEUNG is currently the Philips Chair Professor of Human Resource Management at the China Europe International Business School and a professor at the Ross School of Business at the University of Michigan. Before his recent return to academia, Dr. Yeung served as chief learning officer and subsequently chief HR officer of Acer Group-one of the top 5 PC companies worldwide. Reporting directly to the chairman and CEO, he worked closely with the top management team to radically transform Acer to meet the challenges and opportunities of new business realities.

Dr. Yeung's research interests focus on building organizational capability for strategic implementation, leading and facilitating organizational transformation, and strategic human resource management. He has received research awards from leading human resource associations in the United States: the Yoder-Heneman Personnel Research Award presented by the Society of Human Resource Management (1989) and the Best Research Paper of the Year from the Human Resource Planning Society (1995). In 2002, he also received the Gold Book Award jointly presented by the Ministry of Economic Affairs and the Chinese Management Association in Taiwan. Dr. Yeung also serves as an associate editor of Human Resource Management and is a member of the editorial advisory board of the Harvard Business Review (China).

In addition to research and teaching, Dr. Yeung has also been involved in training and consulting projects for numerous major corporations in Asia and North America, including 7-11, ABB, Acer, AlliedSignal, Applied Materials, BenQ, Boeing, Carrier, China Merchant Group, China Mobile, China Steel, CIMC, CNOOC, Ford Motors, Hewlett-Packard, ICl, ING Antai, Inventec, Philips, Rockwell Automation, Shanghai Petrochemical, Taishin Financial Holdings, TSMC, TCL, and the United Microelectronic Group. He also serves as a board member at Kingdee International Software Group and an advisor to leading multinational and local firms in China.

Due to his contribution in executive education, Dr. Yeung was recognized in 1999 by Business Horizons magazine in the United States as a next-generation "executive development guru." In 2002, Dr. Yeung was elected HR Executive of the Year by SmartFortune magazine in China in recognition of his influential contribution in strategic human resource management in the Greater China region. He also serves as a regional judge for selecting the "Best Employers in Asia," sponsored by Hewitt, the Asian Wall Street Journal, and the Far Eastern Economic Review. 